JAMP: Jurnal Adminitrasi dan Manajemen Pendidikan

Volume 4 Nomor 2 Juni 2021, Hal : 178 - 186

Tersedia Online di http://journal2.um.ac.id/index.php/jamp/

ISSN 2615-8574 (online)

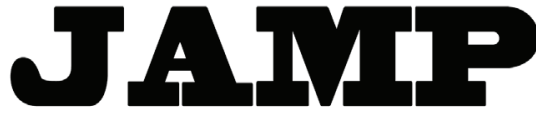

JURNAL ADMINISTRASI DAN MANAJEMEN PENDIDIKAN

\title{
BEST PRACTICE PENJAMINAN MUTU LULUSAN BERBASIS IASP 2020 DI SEKOLAH MENENGAH KEJURUAN
}

\author{
Enung Hasanah \\ Magister Manajemen Pendidikan, FKIP, Universitas Ahmad Dahlan, Yogyakarta \\ E-mail: enung.hasanah@mp.uad.ac.id.
}

\begin{abstract}
Tahun 2020, instrument akreditasi sekolah/madrasah mulai menggunakan Instrumen Akreditasi Satuan Pendidikan 2020 (IASP 2020). Dalam konteks IASP 2020, komponen mutu lulusan merupakan komponen yang memiliki bobot nilai paling tinggi dibandingkan dengan komponen lainnya. Penelitian ini bertujuan untuk mengeksplorasi proses penjaminan mutu lulusan berbasis akreditasi di Sekolah Menengah Kejuruan dengan menggunakan IASP 2020. Penelitian ini menggunakan metode penelitian studi kasus. Partisipan dalam penelitian ini ditentukan dengan metode purposive sampling, dengan kriteria: seluruh warga SMK yang telah mengalami proses penjaminan mutu lulusan dengan menggunakan IASP 2020. Jumlah partisipan dalam penelitian ini sebanyak 16 orang guru dan karyawan. Hasil penelitian menunjukan bahwa proses penjaminan mutu lulusan berbasis akreditasi dilakukan melalui program: 1) Persiapan: pemahaman IASP 2020, pembentukan tim penjamin mutu lulusan; 2) Melakukan EDS mutu lulusan berbasis IASP 2020; 3) Analisis kesenjangan antara hasil EDS dengan kondisi ideal; 4) Pemenuhan gap melalui perbaikan kinerja pada komponen mutu lulusan; 5) Evalusi program ketercapaian kinerja mutu lulusan dan tindak lanjut.
\end{abstract}

Keywords: mutu lulusan; akreditasi; IASP 20203; Sekolah Menengah Kejuruan.

\begin{abstract}
Abstrak: In 2020, the school accreditation instrument began to use the 2020 Education Unit Accreditation Instrument (IASP 2020). In the context of the 2020 IASP, the component of graduate quality is the component that has the highest value weight compared to other components. This study aims to explore the process of quality assurance for accreditationbased graduates in Vocational High Schools using the IASP 2020. This study uses a case study research method. Participants in this study were determined by purposive sampling method, with the criteria: all SMK citizens who have undergone a graduate quality assurance process using IASP 2020. The number of participants in this study was 16 teachers and employees. The results showed that the accreditation-based graduate quality assurance process was carried out through the following programs: 1) Preparation: understanding IASP 2020, forming a graduate quality assurance team; 2) Conducting the 2020 IASP-based graduate quality EDS; 3) Gap analysis between EDS results and ideal conditions; 4) Fulfilling the gap through improving the performance of the graduate quality component; 5) Evaluation of the program for the achievement of the quality performance of graduates and the follow-up.
\end{abstract}

Keywords: graduated qualities; accreditation; IASP 2020; Vocational Senior High School.

Akreditasi merupakan salah satu model penjaminan mutu Pendidikan yang dinilai efektif diberbagai negara (Ryan, 2011; Schomaker, 2015). Di Indonesia, proses akreditasi sekolah/madrasah dilaksanakan oleh badan akreditasi sekolah/madrasah (BAN SM)(Sumarto, 2019), sebuah Lembaga independent di bawah kementrian Pendidikan republic Indonesia. Dalam melaksanakan tugasnya, BAN SM dibantu oleh sekertariat yang menangani pekerjaan-pekerjaan teknis administrative, dan dibantu oleh asesor sebagai pihak yang secara langsung melakukan proses visitasi akreditasi ke sekolah/madrasah. 
Objek penilaian akreditasi meliputi semua proses dan hasil pendidikan yang mencerminkan 8 standar nasional Pendidikan (Awaludin, 2017). Alat yang digunakan oleh asesor untuk mengumpulkan bukti-bukti kinerja penjaminan mutu sekolah/madrasah adalah instrument akreditasi yang disusun oleh BAN SM pusat dan disahkan oleh Mentri pendidikan.

Mulai tahun 2020, proses pengumpulan data akreditasi sekolah telah menggunakan Instrumen Akreditasi Satuan Pendidikan 2020 (IASP 2020) (Hasanah et al., 2020), butir-butir instrument tidak lagi secara eksplisit mengukur kepatuhan Lembaga Pendidikan terhadap 8 SNP, melainkan 8 SNP diramu menjadi 4 komponen utama penilaian yaitu komponen mutu lulusan, komponen guru, komponen proses pembelajaran, dan komponen manajemen sekolah sebagai indicator sekolah yang baik(Beuermann et al., 2018).

Dalam konteks IASP 2020, komponen mutu lulusan merupakan komponen yang memiliki bobot nilai paling tinggi dibandingkan dengan komponen lainnya. Komponen mutu lulusan diyakini sebagai gambaran output Pendidikan yang berhasil dibangun melalui proses Pendidikan yang diselenggarakan oleh sekolah melalui pemanfaatan seluruh sumberdaya yang dimiliki sekolah. Oleh karena itu, semua sekolah harus fokus untuk melakukan penjaminan mutu lulusan agar mampu menghasilkan nilai akreditasi yang maksimal.

Penjaminan mutu lulusan merupakan upaya yang dilakukan oleh sekolah dalam menjamin output pendidikan agar kualitasnya sesuai dengan tujuan, dan visi misi sekolah(Kurland et al., 2010; Metsing et al., 2018), sehingga dapat memenuhi tuntutan kinerja sesuai dengan IASP 2020. Selain itu, penjaminan mutu lulusan merupakan upaya sekolah dalam mempertahankan output mutu Pendidikan untuk menjaga keberlangsungan sekolah agar tetap menjadi pilihan masyarakat (Mariscal, 2005), sebab kualitas mutu lulusan menjadi salah satu hal yang paling banyak dipertimbangkan oleh para orang tua dalam memilih sekolah(Vongsachang et al., 2020).

Mutu lulusan yang harus dikembangkan di sekolah menurut IASP 2020 terdiri dari perkembangan karakter siswa maupun perkembangan kompetensi siswa. Karakter siswa yang perlu dikembangkan menurut IASP 2020 antara lain kedisiplinan siswa (Romero, 2015), perkembangan moral dan religious siswa (Wening \& Hasanah, 2020), sikap Tangguh dan tanggung jawab (Almoayad et al., 2020), sikap terbebas dari perundungan yang dibentuk dari adanya sikap toleransi dan saling menghargai, serta menerima kekurangan masing-masing (Wang et al., 2020).

Pengembangan kompetensi siswa yang dinilai dalam IASP 2020 adalah keterampilan abad 21 yang harus dikembangkan melalui berbagai program pendidikan di sekolah, baik melalui pembelajaran di kelas maupun di luar kelas, juga melalui berbagai kegiatan intra dan ekstrakulikulir. Kompetensi yang dikembangkan dalam IASP 2020 antara lain kemampuan berkomunikasi (Deardorff, 2006), kemampuan kolaborasi (Dietrich et al., 2020), kemampuan berpikir kritis (Padhi \& Mishra, 2020), pengembangan kreativitas dan inovasi siswa (Shrestha \& Dangol, 2019), kemampuan mengekspresikan diri sesuai dengan minat bakat (Rurato \& Gouveia, 2014), dan juga harus ada peningkatan prestasi akademik dari waktu ke waktu (Abudu \& Gbadamosi, 2014).

Dalam proses penjaminan mutu lulusan yang sesuai dengan IASP 2020 diperlukan kesungguhan dan kemampuan sekolah untuk mengembangkan setiap aspek mutu lulusan, baik berupa rencana progam, pelaksanaan program, maupun evaluasi program pengembangan mutu lulusan sesuai tuntutan IASP 2020. Khusus untuk SMK, sekolah diwajibkan memenuhi komponen mutu lulusan untuk menghasilkan siswa yang mampu memperoleh sertifikat uji kompetensi lulusan dari LSP1/LSP2/LSP3 (Raharjo, 2013).

Pemenuhan komponen mutu lulusan berbasis IASP 2020 memiliki karakteristik berbeda jika dibandingkan dengan proses pemenuhan mutu lulusan dengan menggunakan instrument akreditasi sekolah sebelumnya, di sisi lain, belum banyak SMK yang berhasil meraih nilai sempurna untuk pembuktian kinerja penjaminan mutu lulusan berbasis IASP 2020. Hal ini disebabkan karena IASP 2020 relatif baru sehingga belum tersosialisasi dengan baik di seluruh sekolah.

SMK Muhammadiyah Gamping merupakan salah satu SMK yang telah divisitasi dengan menggunakan IASP 2020, dan berhasil mencapai nilai A untuk pemenuhan komponen mutu lulusan. 
Pengalaman SMK Muhammadiyah Gamping dalam melakukan penjaminan mutu lulusan berbasis akreditasi yang menggunakan IASP 2020 dapat menjadi sebuah best practice yang dapat digunakan oleh sekolah-sekolah lain untuk memenuhi hal serupa. Oleh sebab itu penelitian ini bertujuan untuk mengeksplorasi proses penjaminan mutu lulusan yang telah dilakukan oleh SMK Muhammadiyah Gamping berbasis IASP 2020. Untuk menuntun arah penelitian, penulis Menyusun rumusan masalah sebagai berikut: Bagaimana proses penjaminan mutu lulusan yang dilakukan oleh SMK Muhammadiyah Gamping dalam rangka mempersiapkan visitasi akreditasi?

\section{METODE}

Penelitian ini merupakan penelitian studi kasus (Forrest-Lawrence, 2019; Patton, 2012), yang berupaya untuk mengeksplorasi fenomena yang terjadi di suatu lembaga tertentu secara mendalam berdasarkan keterangan-keterangan yang diberikan oleh partisipan dan juga pengamatan lingkungan. Sampel dalam penelitian ini ditentukan dengan menggunakan metode purposive sampling (Jupp, 2015; Teddlie \& yu, 2007), dengan tujuan agar data-data yang diperoleh benar-benar didapatkan dari orang-orang yang memiliki pengetahuan dan pengalaman langsung mengenai fenomena yang sedang diteliti. Kriteria partisipan dalam penelitian ini adalah pihak-pihak yang mengalami secara langsung proses penjaminan mutu sekolah berbasis akreditasi di SMK Muhammadiyah Gamping, yang terdiri Tim manajemen sekolah, guru , dan karyawan di SMK Muhammadiyah Gamping yang telah memiliki pengalaman langsung dalam proses penjaminan mutu lulusan sesuai dengan IASP 2020. Sesuai dengan etika penelitian social, dalam hal ini seluruh data partisipan disamarkan, dan diberi kode nama P1-P16. Jumlah partisipan dalam penelitian ini dapat digambarkan dalam Tabel 1.

Tabel 1. Partisipan

\begin{tabular}{ll}
\hline \multicolumn{1}{c}{ Keterangan } & \multicolumn{1}{c}{ Jumlah } \\
\hline Tim manajemen sekolah & 6 orang \\
Guru & 8 orang \\
Karyawan & 2 orang \\
\hline Total & 16 orang \\
\hline
\end{tabular}

Proses pengambilan data dilakukan melalui FGD secara online melalui zoom meeting selama 2 kali pertemuan yang dilakukan pada bulan Desember 2020, dan juga melalui analisis dokumen. Seluruh data yang dikumpulkan dianalisis dengan menggunakan metode analisis data kualitatif (Cassell \& Bishop, 2019; Kalpokaite \& Radivojevic, 2019), yang secara garis besar terdiri dari empat langkah utama yaitu tahap Inspeksi (pemeriksaan seluruh data secara seksama), Siklus Pengkodean (pengkodean merupakan proses peneliti mencari koneksi data yang dikumpulkan di lapangan), Siklus Kategorisasi (mengumpulkan kode-kode data yang memiliki kesamaan arti), dan tahap Pemodelan (proses Menyusun model data yang disajikan), serta memberikan penjelasan interpretative terhadap semua data secara keseluruhan.

\section{HASIL}

Berdasarkan hasil analisis dokumen dan FGD, diketahui bahwa proses penjaminan mutu lulusan berbasis akreditasi dengan menggunakan IASP 2020 yang dilakukan oleh SMK Muhammadiyah Gamping terdiri dari 5 langkah utama yaitu 1) Tahap perencanaan; 2) Pelaksanaan evaluasi diri sekolah; 3) Analisis gap; 4) Perbaikan kinerja; 5) Evaluasi dan tindak lanjut. Secara ringkas, proses tersebut dapat dilihat dalam Gambar 1. 


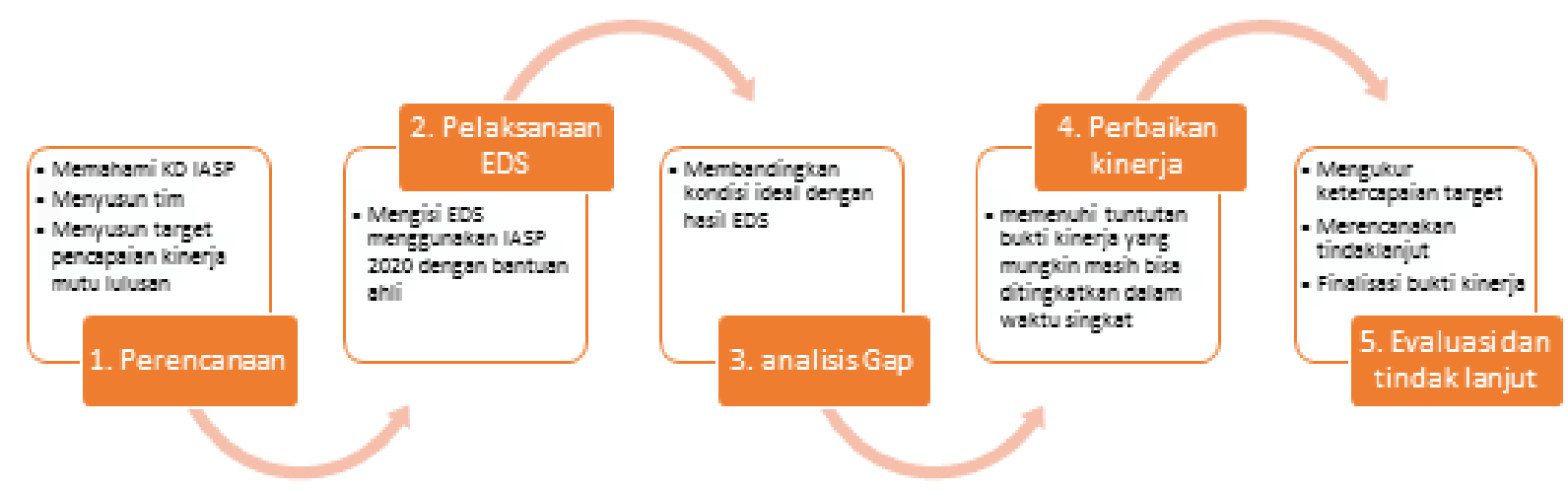

Gambar 1. Proses penjaminan mutu lulusan berbasis IASP 2020

Gambar 1 menunjukan proses penjaminan mutu lulusan yang dilaksanakan oleh SMK Muhammadiyah Gamping dalam rangka mempersiapkan diri untuk proses visitasi yang akan mereka laksanakan. Seluruh proses tersebut dapat dijelaskan sebagai berikut:

\section{Perencanaan}

Awal mula proses penjaminan mutu lulusan dengan menggunakan IASP 2020 sebagai dasar pengembangan mutu di SMK Muhamamdiyah Gamping dilaksanakan sejak adanya pengumuman dari BAN SM DIY yang menyebutkan bahwa SMK Muhammadiyah Gamping sebagai salah satu SMK piloting pelaksanaan akreditasi dengan menggunakan IASP 2020. Pada tahap ini, pihak manajemen sekolah melakukan berbagai persiapan agar seluruh guru dan karyawan memiliki kemampuan dalam mengumpulkan bukti kinerja pemenuhan tuntutan IASP 2020 pada komponen mutu lulusan. Secara umum, kegiatan yang dilaksanakan pada tahap perencanaan sebagai berikut.

(a) Memahami konsep dasar IASP 2020 komponen mutu lulusan. Langkah awal yang dilaksanakan oleh Manajemen sekolah adalah mempelajari konsep dasar IASP 2020 khususnya tentang mutu lulusan. Dalam hal ini, manajemen sekolah mengundang ahli yang memiliki pemahaman mengenai konsep dasar IASP 2020, khususnya mengenai mutu lulusan SMK. Untuk memiliki pemahaman yang tepat mengenai standar penilaian pada komponen mutu lulusan, Sekolah mengadakan In House Training (IHT) dengan tema pelatihan penjaminan mutu sekolah berdasarkan Instrumen Akreditasi Satuan Pendidikan 2020.

Kegiatan $I H T$ yang diselenggarakan oleh pihak sekolah dirancang dengan konsep blended antara teori dan praktik. Pada awal kegiatan, nara sumber menyampaikan beberapa hal terkait perubahanperubahan esensial yang terjadi dalam IASP 2020 yaitu: 1) perubahan paradigma penilaian dari pradigma compliace ke paradigma performance; 2) standar penilaian dalam IASP tidak lagi memuat 8 standar nasional pendidikan (SNP) secara parsial, melainkan telah diramu secara komprehensif menjadi 4 kompnen utama yaitu penilaian terhadap komponen mutu lulusan, mutu pembelajaran, mutu guru dan mutu manajemen sekolah. Semua komponen tersebut menjadi sebuah konsep yang komprehensif karena meliputi berbagai standar di dalamnya. Dari data-data notulensi kegiatan, terlihat bahwa pihak manajemen sekolah melaksanakan beberapa kali IHT untuk meningkatkan pemahaman seluruh warga sekolah mengenai apa yang perlu disiapkan oleh sekolah untuk memenuhi kriteria unggul pada komponen mutu lulusan. Para guru dan kepala sekolah menilai bahwa untuk dapat menyiapkan dokumen-dokumen kinerja yang tepat dalam rangka memenuhi standar mutu lulusan, maka diperlukan pemahaman yang benar mengenai setiap butir yang ada dalam IASP 2020;

(b) Menyusun tim penjaminan mutu lulusan. Kegiatan lanjutan dari IHT yang telah diselenggarakan, pihak manajemen sekolah melakukan evaluasi terhadap hasil pelatihan dengan melakukan wawancara 
langsung kepada para ketua program studi dan para guru mengenai pemahaman mereka tentang esensi IASP 2020 terutama tentang komponen mutu lulusan. Dari hasil wawancara dan diskusi yang dilakukan, kepala sekolah menilai bahwa para guru dan karyawan telah memiliki pemahaman yang cukup baik mengenai esensi penjaminan mutu lulusan berdasarkan IASP 2020. Setelah seluruh pihak terkait dinilai cukup memiliki pemahaman mengenai konsep-konsep penilaian dalam intrumen akreditasi pada komponen mutu lulusan, langkah selanjutnya adalah menyusun tim penjaminan mutu lulusan. Dalam hal ini, kepala sekolah menunjuk beberapa orang yang dinilai memiliki kemampuan untuk mempersiapakan bukti kinerja mutu lulusan.

Tim yang disusun dalam komponen mutu lulusan terdiri dari wakil kepala urusan kesiswaan sebagai coordinator, guru BK, Guru Agama, dan juga beberapa wali kelas. Tim ini bertugas mengumpulkan semua bukti-bukti kinerja terkait penjaminan mutu lulusan. Berdasarkan dokumen SK penugasan tim penjamin mutu lulusan di SMK Muhammadiyah gamping, diketahui seluruh anggota tim telah memiliki job deskripsi dan alur kerja yang jelas, sehingga seluruh anggota dapat bekerja lebih cepat dan tepat sasaran. Job deskripsi tersebut ditulis secara lengkap dan menjadi lampiran di SK Tim. Selain itu, di lampiran SK juga ada alur kerja yang jelas dan sistematis sebagai petunjuk untuk semua pihak dalam melaksanakan tugas. Hambar alur kerja tersebut menunjukan bahwa cara kerja tim sudah diprogamkan dengan sangat rapi dan terarah. Berbagai dokumen penunjang yang menunjukan system rancangan kerja untuk proses penjaminan mutu lulusan ditandatangani oleh kepala sekolah sebagai penanggung jawab keseluruhan program;

(c) Menyusun target pencapaian kinerja mutu lulusan. Proses penjaminan mutu selanjutnya adalah menyusun target pencapaian kinerja pada komponen mutu lulusan. Penetapan target dijadikan sebagai dasar acuan tim untuk menyusun langkah-langkah selanjutnya. Dalam proses penyusunan target pencapaian kinerja, tim melakukan secara demokratis dan kolaboratif. Setiap anggota memiliki kesempatan yang sama untuk mengusulkan berbagai hal terkait target yang mungkin dapat dicapai oleh sekolah dengan mempertimbangkan berbagai potensi dan tantangan yang dimiliki oleh sekolah.

Nilai akreditasi pada periode sebelumnya menjadi salah satu dasar penentuan target pencapaian nilai. Selain itu, anggota tim menyajikan data-data tentang ketersediaan potensi, sumberdaya dan kinerja yang sudah dilakukan oleh sekolah selama beberapa periode untuk memberikan gambaran mengenai kualiats mutu lulusan yang telah dicapai oleh sekolah.

\section{Melakukan Evaluasi Diri Sekolah}

Langkah selanjutnya yang dilakukan oleh tim adalah melakukan evaluasi diri untuk melihat posisi ketercapaian kinerja mutu sekolah yang telah dicapai dalam waktu berjalan. Proses Evaluasi diri dilakukan dengan cara mengisi boring IASP 2020 berdasarkan kinerja sekolah pada aspek mutu lulusan dalam tahun berjalan. Evaluasi diri dilakukan secara objektif yaitu benar-benar menilai setiap ketrcapaian kinerja sesuai dengan standar IASP. Untuk meyakinkan bahwa penilaian EDS telah menunjukan kondisi yang sebenarnya, tim meminta bantuan ahli untuk menilai hasil pekerjaan mereka.

\section{Melakukan analisis gap}

Langkah ketiga setelah evaluasi diri adalah melakukan analisis gap. Pada tahap ini, tim membandingkan hasil EDS dengan target ketercapaian kinerja. Untuk butir-butir tertentu yang dinilai telah memenuhi standar, diberi tanda untuk menemukan mana yang belum sampai target. Tahap analisis gap dianggap tahap yang sangat penting oleh para anggota tim karena dari hasil analisis gap dapat diketahui komponen-kompoenn yang sudah memenuhi target dan belum. Dengan demikian, tim dapat mengidentifikasi bagian-bagian apa saja yang masih harus ditingkatkan. Menurut beberapa partisipan, permasalahan secara umum yang dihadapi sekolah dalam hal penjaminan mutu lulusan, hanya pada pelaporan saja, tetapi untuk esensi baik pengembangan karakter maupun kompetensi sudah dilaksanakan dan memenuhi target ketercapaian. Sehingga, dalam hasil analisis gap diberikan catatan-catatan kecil tentang apa saja yang perlu ditindaklanjuti dan siapa yang akan menindaklanjuti setiap gap yang telah ditemukan. 


\section{Melakukan perbaikan kinerja}

Berdasarkan hasil wawancara dan analisis dokumen perbaikan kinerja, diketahui bahwa secara umum, kekurangan dalam mempersiapkan bukti kinerja penjaminan mutu lulusan di SMK Muhamamdiyah Gamping hanya pada tahap pelaporan. Seluruh aspek sudah dilakuakn dan ada hasilnya, tetapi administrasinya belum ditata dengan baik. Maka Langkah perbaikan kinerja yang mereka lakukan adalah melaksanakan perbaikan pelaporan hasil kinerja. Selain itu, meskipun pada esensi sudah dapat memenuhi target, namun, ketua tim tetap melakukan perbaikan kinerja dengan Menyusun programprogram penguatan karakter dan kompetensi siswa pada tahun berjalan agar saat visitasi nilainya menjadi lebih optimal.

\section{Evaluasi dan tindak lanjut}

Langkah terakhir dalam proses panjaminan mutu lulusan adalah melakuakn evaluasi dan tidak lanjut. Setiap sebulan sekali, tim selalu melaksanakan program evaluasi dan tindak lanjut terhadap hasil pencapaian kinerja tim dalam mempersiapkan komponen mutu lulusan yang sesuai dengan IASP 2020. Proses evaluasi dan tindak lanjut tersebut dilaksanakan secara berkelanjutan, di bawah pengawasan langsung kepala sekolah dan pendampingan dari ahli akreditasi.

\section{PEMBAHASAN}

Hasil penelitian ini menunjukan bahwa manajemen sekolah memiliki kemampuan untuk menciptakan inovasi manajemen untuk memudahkan pihak sekolah dalam memenuhi tuntutan standar mutu dalam instrument akreditasi satuan Pendidikan 2020 yang masih relative baru bagi semua sekolah di Indonesia. Keputusan kepala sekolah yang mendahulukan peningkatan pemahaman instrument melalui in house training dan menghadirkan ahli akreditasi sebagai salah satu sumber pengetahuan, terbukti dapat meningkatkan pemahaman para guru dan karyawan mengenai esensi penilaian mutu lulusan. Hal ini sebagai best practice bagi sekolah lain yang akan melakuakn proses penjaminan mutu lulusan berdasarkan IASP 2020. Pengetahuan yang tepat menjadi dasar yang penting untuk menentukan langkah-langkah penjaminan mutu sekolah. Hal ini sejalan dengan teori Pendidikan bahwa transformasi pendidikan agar lebih mendukung pertumbuhan pendidikan secara langsung melalui pemahaman objek pendidikan secara objektif (Lundahl, 2012).

Proses penjaminan mutu lulusan dilaksanakan secara terprogam dan berkelanjutan, didukung dengan job deskripsi yang jelas, memiliki dampak langsung pada kinerja tim yang lebih rapi dan cepat. Hasil penelitian tersebut sejalan dengan hasil penelitian sebelumnya yang menyebutkan bahwa job deskripsi yang jelas dapat meningkatkan kepuasan kerja karyawan, yang dalam konteks ini adalah apra guru dan tenaga kependidikan (Leon Rohr, 2016; Ramhit, 2019), tingkat kepuasan karyawan secara langsung langsung maupun tidak langsung dapat memengaruhi kinerja mereka.

Hal lain yang juga penting dalam proses penjaminan mutu lulusan adalah Kerjasama tim. Dalam konteks ini, kepala sekolah telah membuat suatu kebijakan kepemimpinan yang baik karena telah mampu mengarahkan para anggotanya agar mau dan mampu bekerjasama dalam sebuah tim. Pentingnya kemampuan dalam bekerja secara tim terbukti efektif dalam menyelesaikan berbagai masalah manajemen(Bodvin et al., 2018; Itohan Oviawe, 2017), terlebih dalam sekolah menengah kejuruan, dimana kolaborasi tidak cukup hanya melibatkan unsur internal, melainkan perlu berkolaborasi dengan pihak eksternal.

Langkah-langkah penjaminan mutu lulusan yang dilaksanakan secara sitematis mulai dari perencanaan, pelaksanaan, evaluasi, dan tindak lanjut, merupakan unsur pendukung ketercapaian nilai mutu lulusan yang tinggi. Hal ini sejalan dengan hasil penelitian yang dilakukan di Cina bahwa perencanaan dan penjaminan mutu yang baik adalah proses penjaminan mutu yang berkelanjutan (Holm et al., 2015).

Hasil penelitian menunjukan bahwa pihak sekolah memiliki kesadaran bahwa langkah pertama yang perlu dilaksanakan dalam rangka menjamin mutu lulusan adalah dengan membuat perencanaan 
yang matang, baik perencanaan tentang stretegi kerja maupun target yang akan dicapai. Perencanaan penjaminan mutu yang dilakukan secara sistematis, terbuka, dan melibatkan semua pihak terkait, terbukti dapat memberikan arah yang lebih pasti tentang semua langkah yang perlu dilakukan untuk mencapai sasaran. Hal ini sejalan dengan hasil penelitian Ibrahim (Sumarto, 2019), bahwa peprencanaan merupakan aspek terpenting dalam proses penjaminan mutu karena perencanaan dapat menjadi acuan untuk kegaitan berikutnya. Dalam hal ini, pihak sekolah menyusun perencanaan secara detil untuk setiap aspeknya, baik konten, waktu, maupun petugas serta langkah antisipasi yang akan dilakukan jika ada hambatan, yang keseluruhannya berada di bawah komando kepala sekolah. Hal tersebut menunjukan bahwa kemampuan manajemen kepala sekolah sekaligus kepemimpinan kepala sekolah memiliki peran yang kuat terhadap suksesnya program-program sekolah (Hasim \& Hasanah, 2020).

Langkah yang kedua setelah perencanaan yaitu pihak sekolah melakukan evaluasi diri untuk mengukur posisi mutu sekolah dengan menggunakan IASP 2020 sebagai standar penilaian mutu lulusan. Kemampuan sekolah dalam melakuakn evaluasi diri sekolah menjadi salah satu faktor pendukung dalam suksesnya sekolah untuk melakukan proses penjaminan mutu (Ibrahim, 2014), sebab dengan melakukan evaluasi diri yang benar dan objektif, maka pihak sekolah dapat mengetahui mutu sekolah yang sebenarnya, mengetahui bagian mana yang perlu di dorong perkembanagnnya, faktor apa yang menjadi penghambat dan pendukung keberhasilan dalam penjaminan mutu lulusan.

Analisis gap merupakan langkah lanjutan setelah pihak sekolah melakukan evaluasi diri. Langkah ini memiliki manfaat untuk mengidentifikasi bagian-bagian mana saja yang perlu ditingkatkan dengan membandingkan antara kondisi existing dengan kondisi ideal yang diharapkan. Analisis gap (Murray et al., 2020), berfungsi untuk memusatkan perhatian dan menentukan skala prioritas dalam proses penjaminan mutu lulusan pada langkah berikutnya dari berbagai aspek yang masih ditemukan adanya kesenjangan.

Langkah penjamiann mutu selanjutnya adalah melakukan perbaikan kinerja, terutama untuk bagian-bagian kinerja yang dinilai masih rendah. Perbaikan kinerja dalam proses penjaminan mutu lulusan, idealnya dilakuakn sesuai dengan visi misi sekolah (Metsing et al., 2018), sehingga kinerja yang dihasilkan sejalan dengan apa yang ditargetkan sebagai standar mutu lulusan di sekolah tersebut.

Hal terakhir yang dilakukan dalam proses penjaminan mutu lulusan adalah dengan melakukan evaluasi dan tindak lanjut. Hal ini merupakan bagian dari sebuah proses penjaminan mutu berkelanjutan, sebab dari hasil evaluasi, pihak manajemen sekolah melakukan tindak lanjut sesuai dengan temuantemuan hasil evaluasi yang telah dilaksanakan (Pascarella et al., 2020; Yongmei Ni, Liz Hollingworth, Andrea Rorrer, 2016)

\section{SIMPULAN}

Berdasarkan hasil penelitian dan pembahasan dapat disimpulkan bahwa proses penjaminan mutu lulusan di sekolah menengah kejuruan perlu dilakukan secara komprehensif baik programnya maupun orang-orang yang terlibat di dalamnya. Pihak manajemen sekolah harus mampu Menyusun Langkahlangkah strategis yang sesuai dengan konteks dan kemampuan sekolah masing-masing. Hal-hal utama yang perlu dikembangkan dalam proses penajmiann mutu lulusan berdasarkan IASP 2020 antara lain perlu pemahaman instrument secara benar; perlu Kerjasama tim; dan perlu melaksanakan fungsi-fungsi manajemen yang didukung oleh kemampuan kepemimpinan yang cocok dengan karakteristik sekolah masing-masing. Selain itu, setiap Langkah proses penjaminan mutu perlu ditindaklanjuti secara baik dan benar agar hasilnya menjadi lebih optimal.

\section{DAFTAR RUJUKAN}

Abudu, K. A. \&, \& Gbadamosi, M. R. (2014). Relationship between teacher's attitude and student's academic achievemnt in senior secondary school chemistry. A case study of ijebu-ode and odogbolu local government area of ogun state. Wudpecker Journal of Educational Research, 3(3), 035-043. 
Almoayad, F., Almuwais, A., Alqabbani, S. F., \& Benajiba, N. (2020). Health professional students' perceptions and experiences of remote learning during the covid-19 pandemic. International Journal of Learning, Teaching and Educational Research, 19(8), 313-329. https://doi.org/10.26803/ijlter.19.8.17

Awaludin, A. A. R. (2017). Akreditasi Sekolah sebagai Suatu Upaya Penjaminan Mutu Pendidikan di Indonesia. SAP (Susunan Artikel Pendidikan). https://doi.org/10.30998/sap.v2i1.1156

Beuermann, D., Navarro-Sola, L., \& Pardo, F. (2018). What is a Good School, and Can Parents Tell? Evidence on the Multidimensionality of School Output. National Bureau of Economic Research Working Paper Series. https://doi.org/10.3386/w25342

Bodvin, K., Verschueren, K., \& Struyf, E. (2018). School counsellors' beliefs regarding collaboration with parents of students with special educational needs in Flanders: Parents as partners or opposites? British Educational Research Journal, 44(3). https://doi.org/10.1002/berj.3333

Cassell, C., \& Bishop, V. (2019). Qualitative Data Analysis: Exploring Themes, Metaphors and Stories. European Management Review, 16(1). https://doi.org/10.1111/emre.12176

Deardorff, D. K. (2006). Identification and assessment of intercultural competence as a student outcome of internationalization. Journal of Studies in International Education, 10(3), 241-266. https://doi. org/10.1177/1028315306287002

Dietrich, N., Kentheswaran, K., Ahmadi, A., Teychene, J., Bessiere, Y., Alfenore, S., Laborie, S., Bastoul, D., Loubiere, K., Guigui, C., Sperandio, M., Barna, L., Paul, E., Cabassud, C., Line, A., \& Hebrard, G. (2020). Attempts, successes, and failures of distance learning in the time of covid-19. Journal of Chemical Education. https://doi.org/10.1021/acs.jchemed.0c00717

Forrest-Lawrence, P. (2019). Case study research. In Handbook of Research Methods in Health Social Sciences. https://doi.org/10.1007/978-981-10-5251-4_67

Hasanah, E., Purnawan, P., Kuat, K., \& Hamidun, E. (2020). Pelatihan penjaminan mutu sekolah berbasis akreditasi di SMK Muhammadiyah 2 Bantul. Prosiding Hasil Pengabdian Kepada Masyarkat, 799-806.

Hasim, W., \& Hasanah, E. (2020). The Role of Principal Leadership in Preventing COVID-19 Transmission at SMA Muhammadiyah 2 Karang Tengah Buay Madang Timur Indonesia. Asian Journal of Education and Social Studies, 11(1), 1-10. https://doi.org/10.9734/ajess/2020/v11i130279

Holm, T., Sammalisto, K., \& Vuorisalo, T. (2015). Education for sustainable development and quality assurance in universities in China and the Nordic countries: A comparative study. Journal of Cleaner Production, 107. https://doi.org/10.1016/j.jclepro.2014.01.074

Ibrahim, H. A.-H. (2014). Quality Assurance and Accreditation in Education. Open Journal of Education. https:// doi.org/10.12966/oje.06.06.2014

Itohan Oviawe, J. (2017). Bridging Skill Gap to Meet Technical, Vocational Education and Training SchoolWorkplace Collaboration in the 21 \&lt;sup\&gt;st\&lt;/sup\&gt; Century. International Journal of Vocational Education and Training Research, 3(1). https://doi.org/10.11648/j.ijvetr.20170301.12

Jupp, V. (2015). Purposive Sampling. In The SAGE Dictionary of Social Research Methods. https://doi. org/10.4135/9780857020116.n162

Kalpokaite, N., \& Radivojevic, I. (2019). Demystifying qualitative data analysis for novice qualitative researchers. Qualitative Report, 24(13).

Kurland, H., Peretz, H., \& Hertz-Lazarowitz, R. (2010). Leadership style and organizational learning: The mediate effect of school vision. Journal of Educational Administration, 48(1). https://doi. org/10.1108/09578231011015395

Leon Rohr, S. (2016). Harnessing the power of the job description. Human Resource Management International Digest, 24(6). https://doi.org/10.1108/HRMID-09-2015-0143

Lundahl, L. (2012). Educational Theory in an Era of Knowledge Capitalism. Studies in Philosophy and Education, 31(3). https://doi.org/10.1007/s11217-012-9304-9

Mariscal, J. (2005). Digital divide in a developing country. Telecommunications Policy, 29((5-6)), 409-428. https://doi.org/10.1016/j.telpol.2005.03.004

Metsing, I. T., Hansraj, R., Jacobs, W., \& Nel, E. W. (2018). Review of school vision screening guidelines. In African Vision and Eye Health (Vol. 77, Issue 1). https://doi.org/10.4102/aveh.v77i1.444

Murray, C., Heinz, M., Munday, I., Keane, E., Flynn, N., Connolly, C., Hall, T., \& MacRuairc, G. (2020). Reconceptualising relatedness in education in 'Distanced' Times. European Journal of Teacher Education. https://doi.org/10.1080/02619768.2020.1806820 
Padhi, L. K., \& Mishra, D. (2020). Learning how to learn. International Journal of Web-Based Learning and Teaching Technologies, 15(3), 46-59. https://doi.org/10.4018/ijwltt.2020070104

Pascarella, G., Strumia, A., Piliego, C., Bruno, F., Del Buono, R., Costa, F., Scarlata, S., \& Agrò, F. E. (2020). COVID-19 diagnosis and management: a comprehensive review. In Journal of Internal Medicine (Vol. 288, Issue 2). https://doi.org/10.1111/joim.13091

Patton, M. Q. (2012). Qualitative research and evaluation methods (3rd ed.). Sage.

Raharjo, S. B. (2013). Evaluasi trend kualitas pendidikan di indonesia. Jurnal Penelitian Dan Evaluasi Pendidikan. https://doi.org/10.21831/pep.v16i2.1129

Ramhit, K. S. (2019). The impact of job description and career prospect on job satisfaction: A quantitative study in mauritius. SA Journal of Human Resource Management, 17. https://doi.org/10.4102/sajhrm.v17i0.1092

Romero, L. S. (2015). Trust, behavior, and high school outcomes. Journal of Educational Administration. https:// doi.org/10.1108/JEA-07-2013-0079

Rurato, P., \& Gouveia, L. B. (2014). The importance of the learner's characteristics in distance learning environments: A case study. Iberian Conference on Information Systems and Technologies, CISTI, 1-6. https://doi.org/10.1109/CISTI.2014.6876960

Ryan, T. (2011). Quality assurance in higher education: A review of literature. Higher Learning Research Communications. https://doi.org/10.18870/hlrc.v5i4.257

Schomaker, R. (2015). Accreditation and quality assurance in the Egyptian higher education system. Quality Assurance in Education. https://doi.org/10.1108/QAE-08-2013-0034

Shrestha, M., \& Dangol, R. (2019). Learning readiness and educational achievement among school students. Indian Psycology, 7(2), 467-476. https://doi.org/10.25215/0702.056

Sumarto, S. (2019). Peran dan kredibilitas badan akreditasi nasional sekolah/madrasah (ban s/m) mewujudkan sekolah efektif melalui manajemen mutu. Jurnal Literasiologi. https://doi.org/10.47783/literasiologi.v1i1.6

Teddlie, C., \& yu, F. (2007). Mixed Methods Sampling: A Typology With Examples. Journal of Mixed Methods Research. https://doi.org/10.1177/2345678906292430

Vongsachang, H., Friedman, D. S., Inns, A., Kretz, A. M., Mukherjee, M. R., Callan, J., Wahl, M., Repka, M. X., \& Collins, M. E. (2020). Parent and Teacher Perspectives on Factors Decreasing Participation in School-Based Vision Programs. Ophthalmic Epidemiology, 27(3). https://doi.org/10.1080/09286586.2020.1730910

Wang, Y., Wang, Y., Chen, Y., \& Qin, Q. (2020). Unique epidemiological and clinical features of the emerging 2019 novel coronavirus pneumonia (COVID-19) implicate special control measures. In Journal of Medical Virology. https://doi.org/10.1002/jmv.25748

Wening, M. H., \& Hasanah, E. (2020). Counseling Service Management in Efforts to Help the Potential Development of High School Students. Randwick International of Social Science Journal. https://oi.org/10.47175/rissj. v1i3.110

Yongmei Ni, Liz Hollingworth, Andrea Rorrer, and D. P. (2016). The evaluation of educational leadership preparation programs. In Handbook of research on the education of school leaders (pp. 285-307). Routledge. https://doi.org/15031-0153 